\title{
Simple calibration of the extension strain criterion for its use in numerical modelling
}

\author{
V. Louchnikov Coffey Mining Pty Ltd, Australia
}

\begin{abstract}
Calibrating numerical models is generally considered to be a rather time-consuming exercise which commonly involves a number of activities such as obtaining instrument readings, observing and mapping progressive rock mass damage, conducting various rock tests and surveying. While it is certainly absolutely necessary to undertake all these actions to make numerical models a working tool, quite often site personnel have no time or resources dedicated for a proper calibration process. In this paper, a simple technique of measuring fractures in drill holes around development drives and then relating the damage patterns to the extension strain contours modelled in a boundary element method (BEM) code is discussed. This technique has been used by the author at a number of operations and was found to be practically effective. A case study is presented where such calibration is shown to be instrumental in deciding on the optimal mining sequence in overstressed ground.
\end{abstract}

\section{Introduction}

One of the key issues in numerical modelling is validation of a model. Numerical models can be a useful tool assisting in engineering solutions, but are only valid if calibrated properly. The validation process defines credibility of the model by demonstrating its ability to replicate actual performance as close as possible. Applicability of a particular model to solve physical problems can be defined by the following three steps:

- Creation of a base model.

- Calibration/validation of the model.

- Application of the validated model as an analytical tool.

There are a number of techniques employed for calibrating numerical models, such as 'direct', 'indirect', 'trial and error', 'steepest descent', etc. In this paper, the 'trial and error' method is used, which comprises assigning selected values to some input parameters, running the model and finally comparing the output results with measured specific values as well as observed material behaviour. The process is iterative. Once satisfactory estimates of the input parameters have been obtained, the model's validity is further tested by applying the ultimate parameters to a number of model runs under various boundary conditions. Only after the model consistently matches behaviour of the physical system, it is considered valid and can be applied for analytical simulations.

In rock mechanics context, a properly validated rock mass model can be reliably used for predicting stressinduced fracturing around excavations. Such models can assist a mining engineer in selecting ground support systems, optimising excavation size and making decisions on stope extraction sequence.

\section{Extension strain criterion}

There are a number of intact rock failure criteria developed over the years by various authors, from classical Mohr-Coulomb envelope (Coulomb, 1779) and Griffith's crack (Griffith, 1924) to more recent ones such as: 'Fairhurst generalised failure criterion' (Fairhurst, 1964), 'Franklin's curved criterion' (Franklin, 1971), 'Modified Hoek-Brown criterion for intact rock' (Hoek and Brown, 1980), 'Sheorey brittle failure criterion' (Sheorey et al., 1989) and a few others less known. One downside with all these theories is that 
they include only major and minor principal stress components in their formulation, thus implying the rock fails predominantly in shear. But what we often see in deep underground mines are layers of parallel fractures formed around excavations - a type of failure commonly called 'spalling' (Figure 1). It is now universally accepted that such fractures (termed 'extension fractures') are caused by high compressive forces. It was found that this type of failure is not shear related, but rather exhibits strongly tensile nature (e.g. Fairhurst and Cook, 1966; Kuijpers, 2000; Ndlovu and Stacey, 2007). Extension fracturing can be described by an 'extension strain criterion' proposed by Stacey (1981). Unlike the criteria mentioned above, the extension strain accounts for all three stress components thus implying that tensile fracturing will occur even if all stress components are compressive. It has to be noted that the original term for the extension strain criterion was 'limiting tensile strain criterion' (Stacey and De Jongh, 1977), thus highlighting its tensile nature. The criterion is stated as: 'the fracture of the rock will occur in indirect tension when the tensile strain exceeds a limiting value which is dependent on the properties of the rock' (Stacey, 1981):

$$
\varepsilon_{3} \geq \varepsilon_{c}
$$

where:

$$
\begin{array}{lll}
\varepsilon_{3} & =\text { extension strain. } \\
\varepsilon_{c} & =\text { critical value of the extension strain. }
\end{array}
$$

Extension strain is effectively the strain in the direction of the minor principal stress expressed by the following equation:

$$
\varepsilon_{3}=\frac{1}{E}\left[\sigma_{3}-v\left(\sigma_{1}+\sigma_{2}\right)\right]
$$

where:

$$
\begin{array}{ll}
\sigma_{1}, \sigma_{2}, \sigma_{3} & =\text { principal stress tensor components (MPa). } \\
E & =\text { Young's modulus of intact rock (MPa). } \\
v & =\text { Poisson's ratio. }
\end{array}
$$

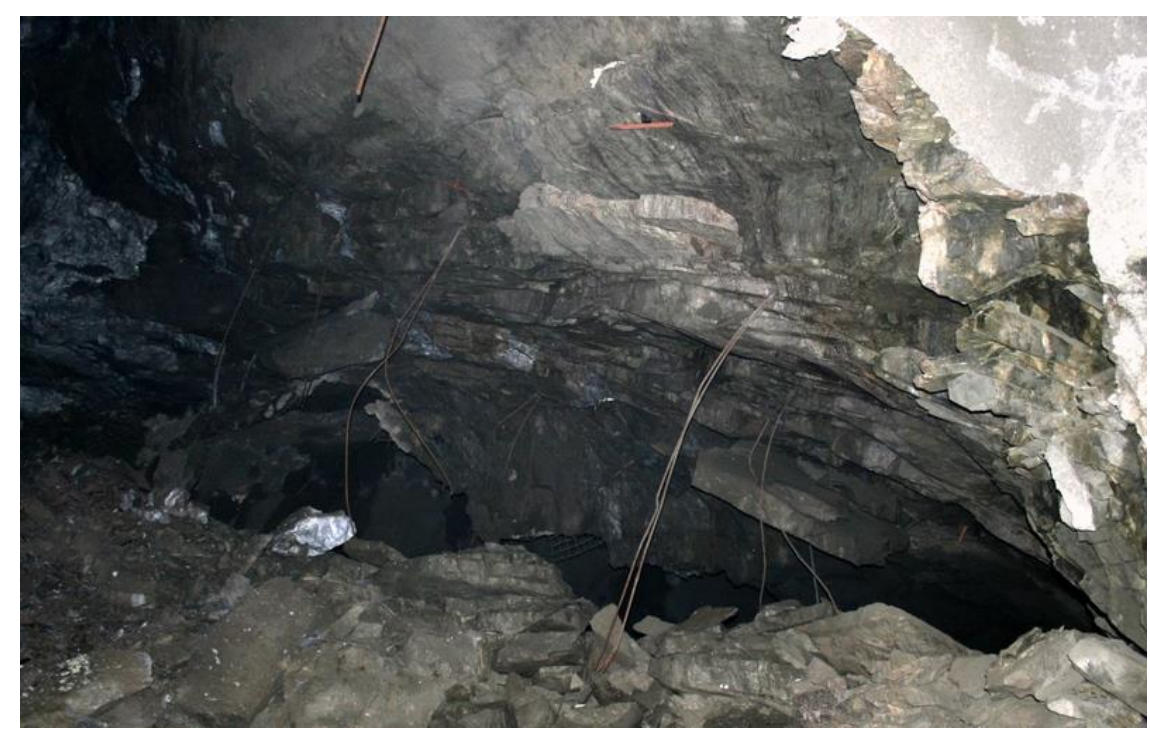

Figure 1 Arching tensile fracturing (spalling) developed in the back of an open stope

Tensile fractures form in planes perpendicular to the direction of the minor principal stress. Extension strain criterion can be used for a wide range of rocks, from strong and brittle through to soft rocks such as coal (e.g. Ndlovu and Stacey, 2007).

Spalling itself may not represent a significant rockfall hazard if there is some kind of surface support present. However, extensional fracturing can interact with natural discontinuities in rock - this can lead to a 
sizable ground fall. Therefore one of the most important tasks when selecting a ground support system, especially for high stress conditions, is to estimate the depth of spalling, thus ground support is designed accordingly, ensuring rock bolts have sufficient anchorage beyond the fractured zone.

\section{$3 \quad$ Extension strain criterion in numerical modelling}

One of the most widely used numerical modelling packages in Australian underground operations is the BEM code Map3D (Wiles, 2011), although a range of commercially available packages can be applied to estimate the depth of rock fracturing. The process involves building a model and then calibrating it against some measured or observed criteria. Once calibrated, the model can be used for predictive analysis. To obtain extension strain contours in microstrain $(\mu \varepsilon)$ units, Equation (2a) will be written in Map3D as:

$$
-1 / E^{*}\left(s 3-v^{*}(s 1+s 2)\right) * 1000000
$$

Note; $E$ and $v$ should be typed in as real numbers, e.g. 75,000 (in $\mathrm{MPa}$ ) and 0.26 respectively, and can be initially set up equal to the rock test results. Extensions are negative strains, but it is common to present them as positive values, hence the minus sign in front of the equation.

\section{$4 \quad$ Calibration of extension strain}

To quantify damage in the rock mass, obviously it should be measured. There are a number of instruments that can be utilised to measure deformations or strains. Although some of these instruments can provide very accurate data, there are some issues associated with using these tools routinely at mine sites, such as instrument availability, specialised installation, risk of damage and history of monitoring. But what if site personnel want to quantify the rock fracturing right now, to be able to build and calibrate a model within the next couple of days? In the author's experience from a number of operations, the simplest tool which can measure depth of fracturing around underground excavation is a steel tape measure. This tool can be used in measuring the depth to the fractures in production blastholes, which are generally drilled in rings across a drive. The end-clip of the steel tape is bent $90^{\circ}$ and is $0.5 \mathrm{~mm}$ thick (Figure 2), so when it slides along the wall of a borehole, it is possible to detect cracks as small as $0.5 \mathrm{~mm}$ wide.

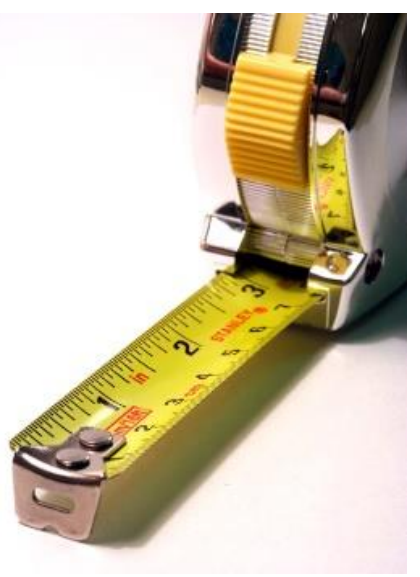

Figure 2 End-clip of a steel tape

This technique can be used in any up- or downhole, as long as the hole is slightly inclined. The extent of fracturing around a development drive is equal in backs and floors, as long as the rock type is the same. Therefore, if fractures are measured in downholes, the same damage pattern can be implied in the backs (assuming the drive backs are flat; in arched backs the roof curvature needs to be accounted for). An example of plots of measured fractures is presented in Figure 3 . Here, a number of production downholes were surveyed using the tape measure. All holes had circumferential cracks close to the collar, the closer to the excavation perimeter, the more open the fractures. Depths to all detected cracks were recorded, plotted and then superimposed on the extension strain contours. By modifying elastic properties in the 
Map3D model ( $E$ and $v$ in Equation (2b)), the desired match between $\varepsilon_{3}$ contours and distances to cracks was obtained.

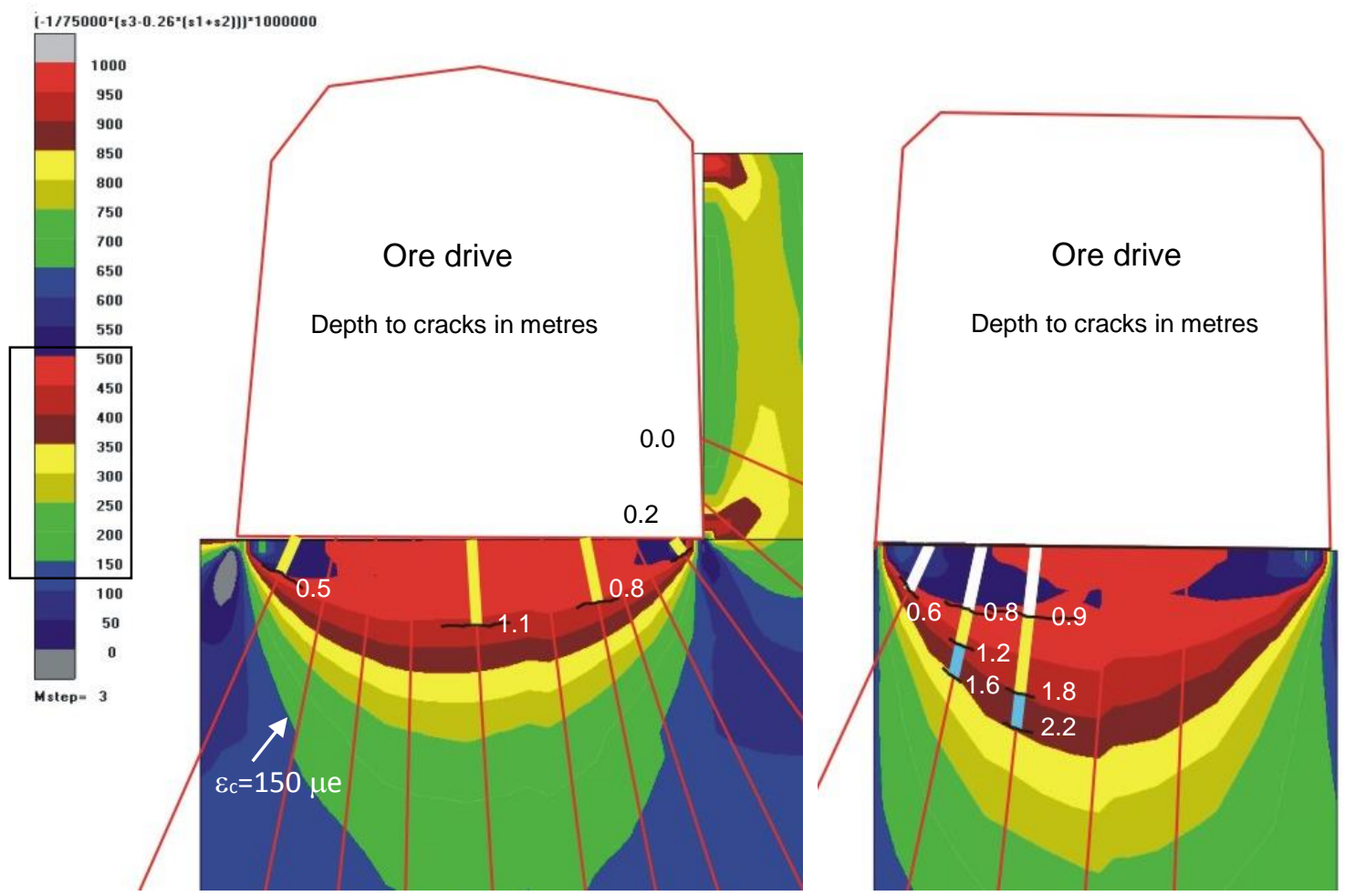

Figure 3 Fractures in production ring holes superimposed on extension strain contours

As an outcome of such calibration process a site-specific extension strain criterion can be developed. The recommended elastic properties for future modelling in each geotechnical domain can be specified (Table 1). The fracture intensity with reference to corresponding extension strain values are presented in Table 2. Ground support required at each damage level is also specified in this table. Stacey (1981) presented a list of critical values of extension strain for a number of rock types, ranging between 73 and $175 \mu \varepsilon$. He also made an assumption that continuous fractures would develop at approximately double the extension strain. Referring to Table 2, the first detectable fractures were observed at 250-350 $\mu \varepsilon$; therefore it could be assumed that the critical extension strain in our case is about $150 \mu \varepsilon$. Elsewhere in Western Australian mines similar critical extension strain values were reported, e.g. around $300 \mu \varepsilon$ crack initiation strain (G. Sweby, pers. comm., 2007).

Table 1 Calibrated elastic properties for numerical modelling

\begin{tabular}{ccccccc} 
& \multicolumn{2}{c}{ Ore } & \multicolumn{2}{c}{ Footwall } & \multicolumn{2}{c}{ Hangingwall } \\
& Lab Tests & Map3D & Lab Tests & Map3D & Lab Tests & Map3D \\
\hline UCS, MPa & 170 & 130 & 150 & 130 & 125 & 130 \\
E, GPa & 85 & 75 & 80 & 75 & 80 & 75 \\
$v$ & 0.26 & 0.26 & 0.28 & 0.26 & 0.28 & 0.28 \\
\hline
\end{tabular}


Table 2 Site-specific extension strain criterion

\begin{tabular}{|c|c|c|c|}
\hline Rock Mass Conditions & $\begin{array}{l}\text { Extension } \\
\text { Strain } \varepsilon_{3}\end{array}$ & Crack Width & Ground Support Required \\
\hline Crushed & $>500 \mu \varepsilon$ & $>5 \mathrm{~mm}$ & Stope crowns should be cable bolted. \\
\hline Heavily broken & $450-500 \mu \varepsilon$ & up to $5 \mathrm{~mm}$ & $\begin{array}{l}\text { If } 500 \mu \varepsilon \text { contour is at the distance of } \\
0.5-1.5 \mathrm{~m} \text { from the excavation profile, } 2.4 \mathrm{~m} \\
\text { rockbolts with } 50 \mathrm{~mm} \text { fibrecrete are } \\
\text { required. For depths up to } 0.5 \mathrm{~m}, 2.4 \mathrm{~m} \\
\text { rockbolts with mesh will suffice (temporary } \\
\text { openings only). If depth of the } 500 \mu \varepsilon \\
\text { contour is greater than } 1.5 \mathrm{~m} \text {, cablebolts are } \\
\text { required in addition to the primary support. }\end{array}$ \\
\hline Broken & $350-450 \mu \varepsilon$ & up to $2 \mathrm{~mm}$ & $\begin{array}{l}\text { These are typical conditions in most of } \\
\text { development drives below } 700 \mathrm{~m} \text {. } \\
\text { Supportable by } 2.4 \text { m rockbolts and mesh. } \\
\text { Fibrecrete to replace mesh for long-life } \\
\text { openings. }\end{array}$ \\
\hline Fractured & $250-350 \mu \varepsilon$ & $\sim 0-1 \mathrm{~mm}$ & Supportable by $2.4 \mathrm{~m}$ rockbolts and mesh. \\
\hline $\begin{array}{l}\text { Fracture initiation }= \\
\text { critical extension strain }\end{array}$ & $\varepsilon_{c}=150 \mu \varepsilon$ & Not detectable & Supportable by $2.4 \mathrm{~m}$ rockbolts and mesh. \\
\hline
\end{tabular}

The calibrated criteria should be periodically reviewed, and where possible supported by other observations such as the one presented in Figure 4. Here arching fractures were observed in the floor of a cross-cut after a stope was mined out. Extension strain was modelled in Map3D and calibrated against the measured depth of fracturing. The rock type in this particular case relates to the 'hangingwall' as specified in Table 1.
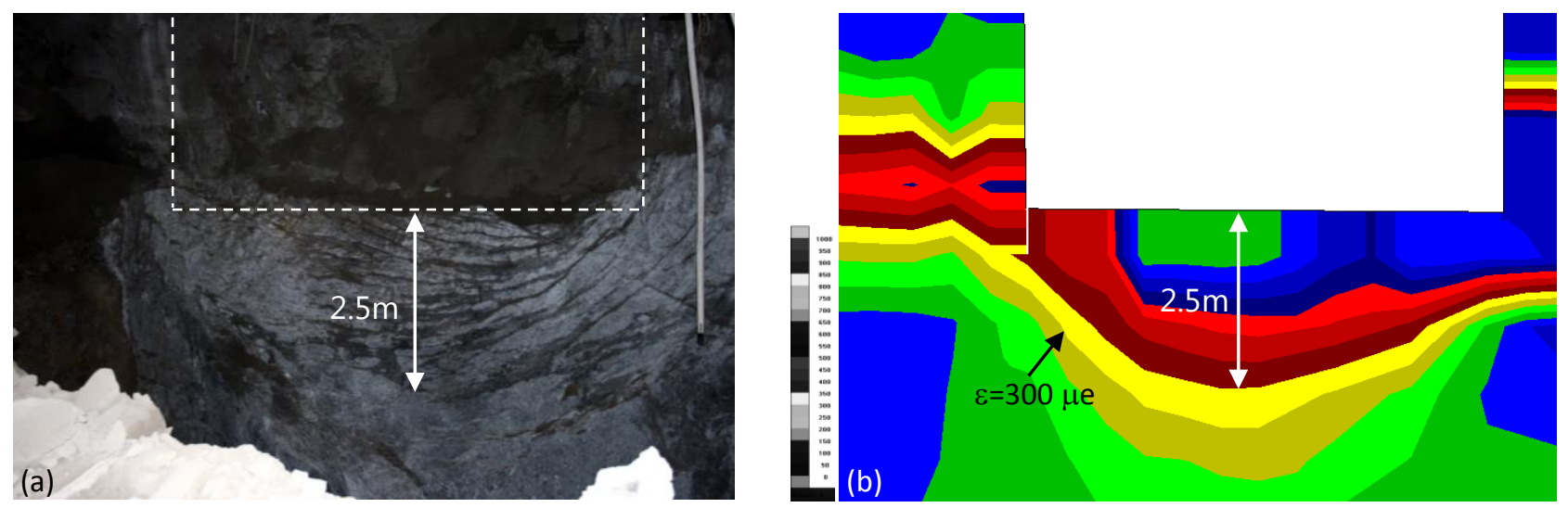

Figure 4 Arching cracks. View across an open stope from a cross-cut looking at hangingwall (crosscut was developed about $3 \mathrm{~m}$ past the hangingwall contact): a) depth of fracturing as measured by surveyors; b) extension strain distribution

Case study - z41 stope

\section{1 Extracting highly stressed stoping block}

A primary-secondary long hole open stoping method was employed at one of the underground mines in Australia: first, the primary stopes are extracted followed by backfilling with cemented fill; then the 
secondaries are extracted and filled with waste rock. This method was reasonably cost-effective until operation moved to deeper levels, where $\sigma_{1}$ reached $70 \mathrm{MPa}$ while $\sigma_{1} / \sigma_{3}$ ratio was around 3. The $994 \mathrm{z} 41$ stope was a secondary stope positioned between the two mined out and backfilled stopes $z 38$ and $z 43$ (Figure 5). The problem of high stress in the $z 41$ had been previously anticipated when Map3D modelling was conducted prior to the stope extraction. Excessive fracturing was predicted in 'pendant pillars' 964-934 and 934-904 based on the extension strain criterion calibrated as per details presented in Tables 1 and 2. The modelled strains were expected to be well above $500 \mu \varepsilon$ thus classifying ground as 'crushed rock' according to Table 2 . This prediction was soon confirmed when production moved to the middle block of the stope, 964-934, where serious stress issues were encountered with production holes squeezing shortly after they had been drilled, Figure 6. Mining the 964-934 block was a real challenge and a number of measures were undertaken, such as bringing the slot up metre by metre, drilling additional rings, charging immediately following drilling and a strictly controlled firing sequence. Eventually this block was fully extracted although with significant production delays due to the need to spread the broken dirt along the drive on the bogging level to inspect for any unfired explosives. A number of stoppages were also necessary due to the increased seismicity in the area.

Based on the back analysis conducted on the $\mathbf{7 1}$ performance and applying the site-specific extension strain criterion, it was concluded that severe hole squeezing and shearing can be expected when extension strain exceeds $500 \mu \varepsilon$.

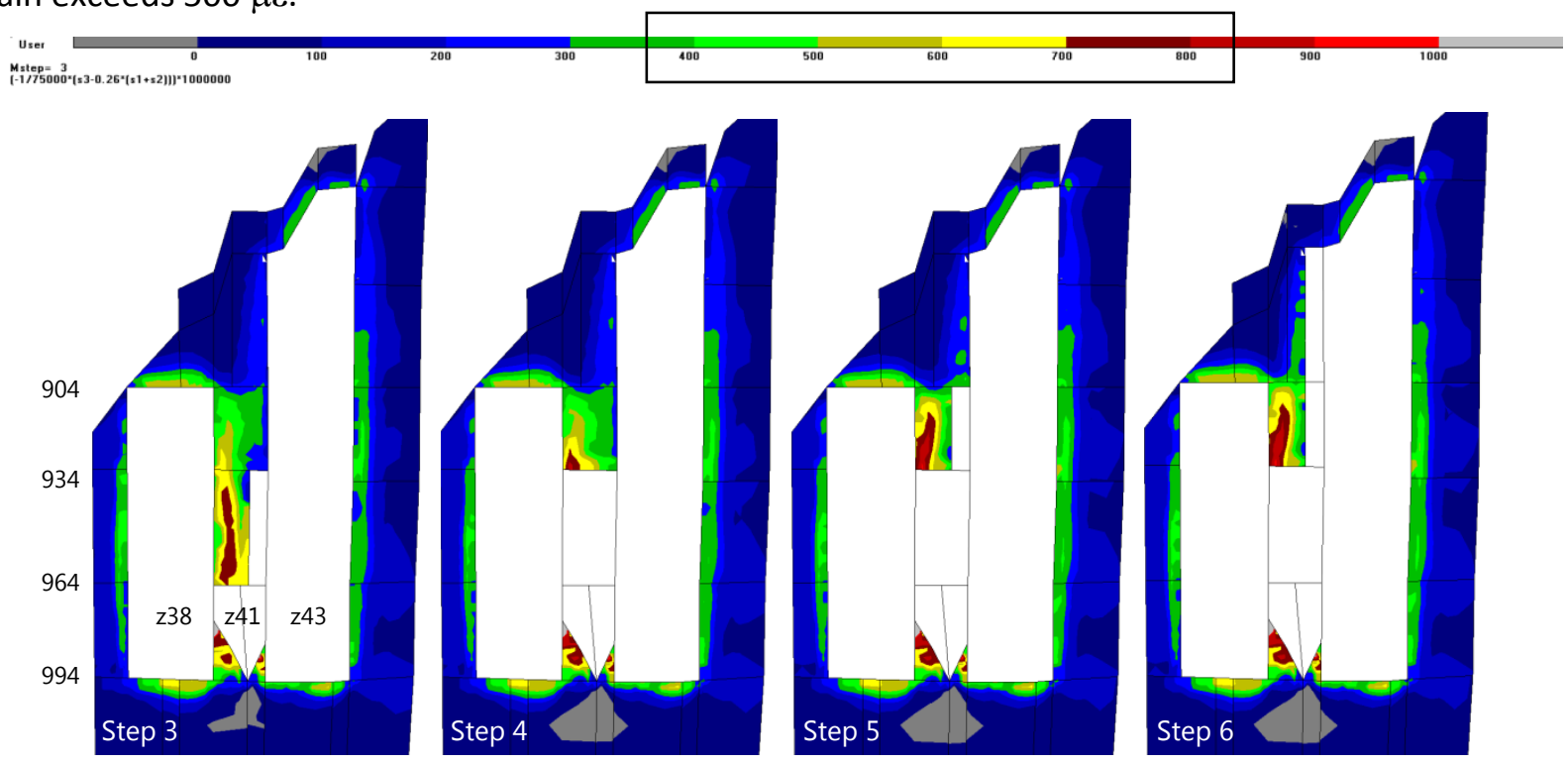

Figure $5 \quad \varepsilon_{3}$ contours showing high degree of fracturing in $994 z 41$ (400 to over $700 \mu \mathrm{e}$ ). Severe squeezing in blastholes was expected in 600-800 $\mu$ e zones (dark coloured contours inside pillar)

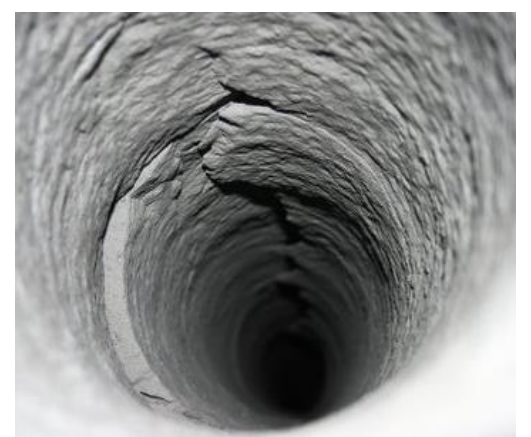

Figure 6 Severely squeezed and sheared production blastholes in 964-934 panel 


\section{2 Pre-conditioning top block}

Having experienced significant hole closing while drilling and charging the 964-934 block and after comparing the degree of straining in this block and the one above, it would be reasonable to assume similar, if not worse, conditions when drilling 934-904 panel. To minimise the risk of troublesome drilling and charging, the 934-904 block had to be shielded from the stress field. The most effective stress management technique is pre-conditioning, whereby ground is fractured along the stope wall so that the stress trajectories are diverted to the more competent ground thus blastholes can be drilled in a stress shadow.

Two types of pre-conditioning technique were considered:

- line drilling

- pre-splitting.

Line drilling would involve a row of $89-102 \mathrm{~mm}$ diameter uncharged holes drilled along the stope's hangingwall with hole spacing of four times the diameter, i.e. $0.35 \mathrm{~m}$. Under the excessive stress the rock between holes acts as a stress concentrator promoting fracture development between holes, thus creating an extensive plane of weakness. The main benefit of this technique is that there is no damage to the hangingwall. However, there are a number of downsides to be expected: a) high precision drilling is required; b) high cost; c) time-consuming; d) effective only in relatively homogenous rock.

Having weighed the pros and cons of this technique, the line drilling was decided to be impractical in the current situation. Hence the pre-splitting method was considered to be more favourable as it is less susceptible to hole deviation and doesn't lead to high drilling costs.

Dyno Nobel Blaster's Handbook (2010) recommends spacing for pre-split holes as 12 times the hole diameter, i.e. $1.2 \mathrm{~m}$ for $102 \mathrm{~mm}$ holes. This seemed to be somewhat too close, as a fully coupled $0.8 \mathrm{~g} / \mathrm{cc}$ emulsion in a $102 \mathrm{~mm}$ blasthole creates a radial zone of crushed rock up to $1.5 \mathrm{~m}$ (as calculated by Holmberg and Persson (1978) equations), thus a $3 \mathrm{~m}$ spacing was chosen. Decoupling was not advised, as there were some concerns whether the decoupled charges would crack the ground enough to create a fractured zone. A decision was made to use already drilled holes instead of drilling the new ones, i.e. to charge those holes closest to the hangingwall (Figure 7). This is certainly not the best solution, but it was considered adequate at the time. A couple of relief holes were drilled between the pre-split holes. This was done to ensure tensile stresses were developed between the holes from interaction of incoming and reflected shock waves.

The pre-split holes were fired simultaneously with the final blast of the 964-934 panel. Upon inspection of the 904 level immediately after firing, the following was observed:

- Collars of two holes cratered up to $1 \mathrm{~m}$ deep (Figure 8). Apparently, the stemming length was not adequate (recommended $3 \mathrm{~m}$, but reportedly it was much shorter). Also, it was found that the emulsion density used was $1.0 \mathrm{~g} / \mathrm{cc}$ instead of the recommended $0.8 \mathrm{~g} / \mathrm{cc}(1.0 \mathrm{~g} / \mathrm{cc}$ was the lowest available from the supplier).

- There was considerable ongoing rock noise in the area during the few hours following blasting suggesting that pre-splitting had done what it was supposed to, i.e. shifted the stress concentration to the stope crown above 904 level.

- Some cracks were evident in the floor between the uncharged holes in the pre-splitting plane (Figure 9).

Drilling of the rest of the production holes in the 934-904 stoping block (drilled as downholes from the 904 level) proceeded once the stope had been bogged clean. No further hole squeezing was experienced. Charging and firing also continued without any issues. The main concern was the risk of damage to the hangingwall from pre-splitting, however after the stope had been mined and cavity monitoring system (CMS) survey taken, no damage to the wall was observed. Therefore it could be concluded that the pre- 
conditioning was applied relatively successfully. 'Relatively' because the drill rig operators experienced some problems when drilling holes in the fractured zone - holes were getting blocked frequently. Eventually a number of holes were not charged (this resulted in some underbreak on the hangingwall).

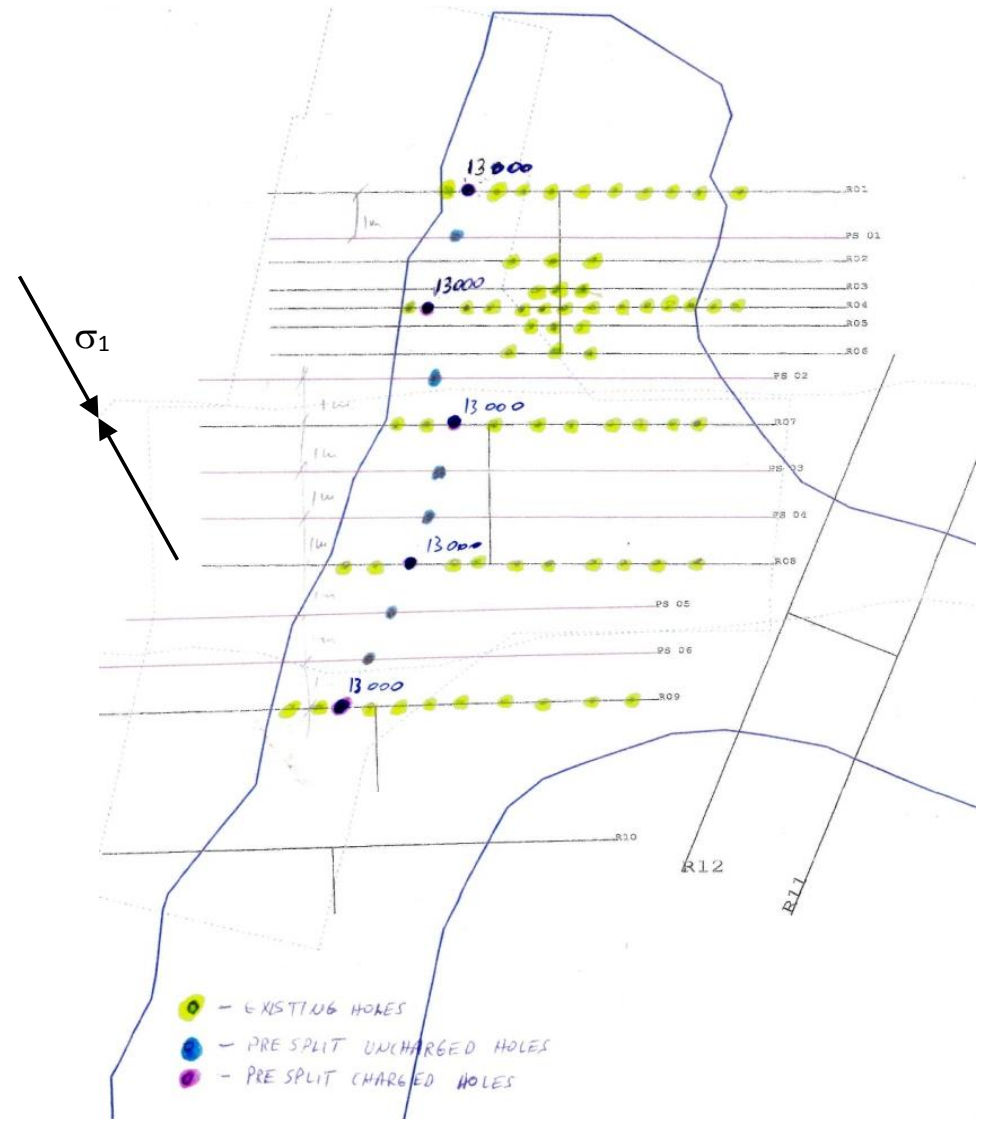

Figure 7 Pre-split holes in 904 level (drilled as downholes to 934)

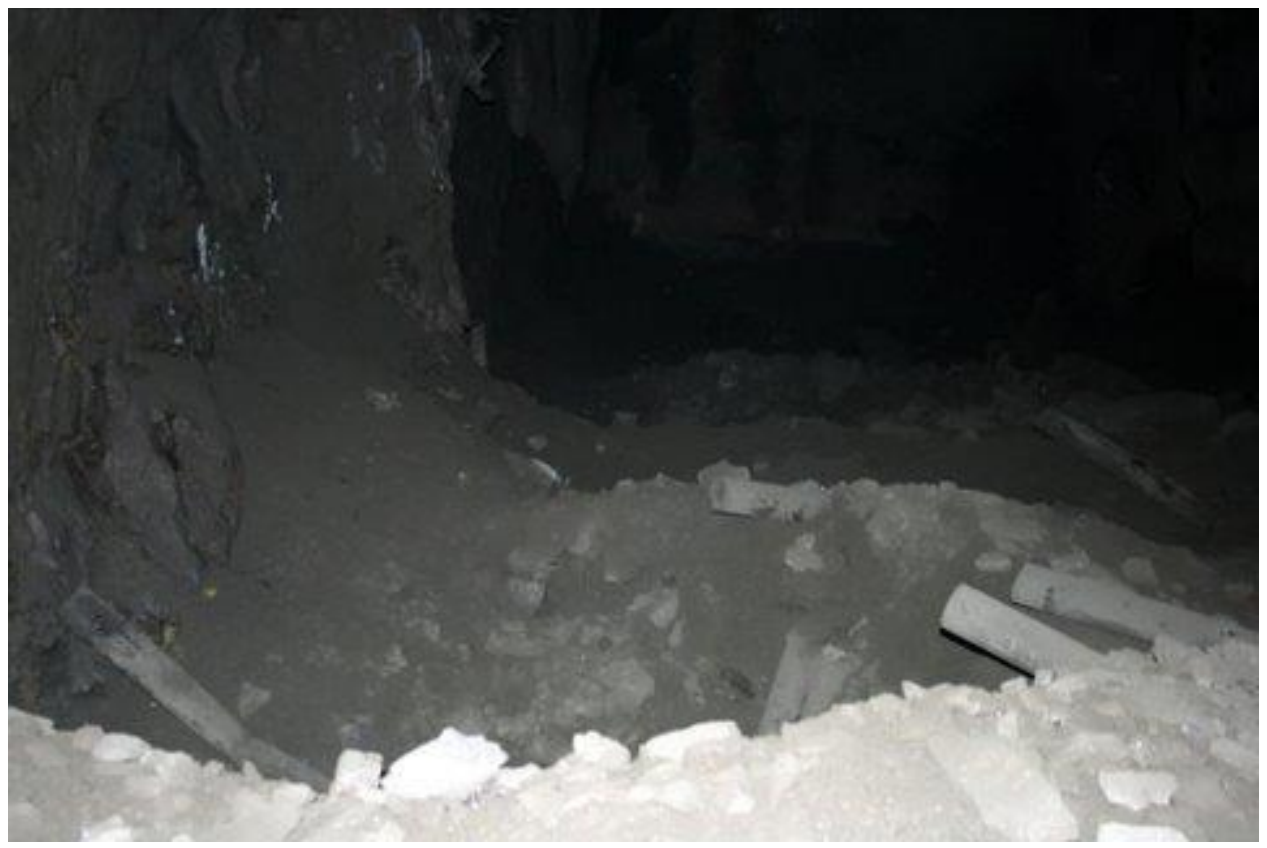

Figure 8 Two craters around collars of pre-split holes in 904 

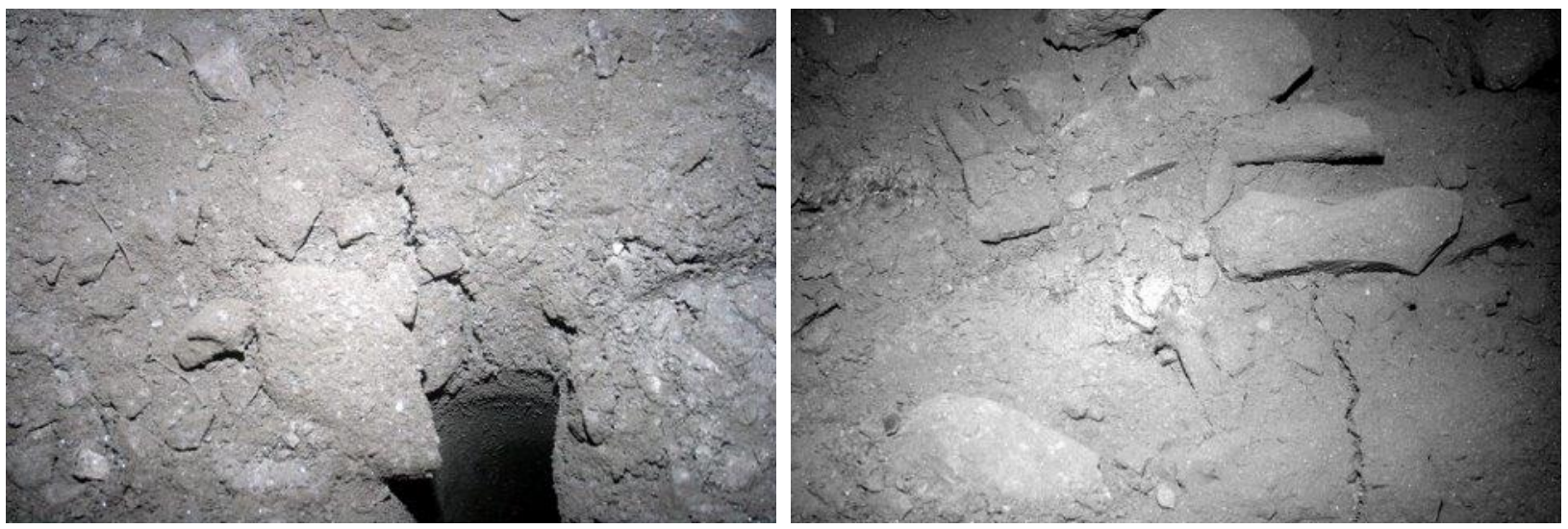

Figure 9 Cracks in floor in pre-split zone

\section{3 Future applications of pre-splitting technique}

One of the main decisions made in relation to the future mining strategy and based on the extension strain criterion applied to the 'primary-secondary' stoping method, was that this sequence could not be used to extract the other stopes in this orebody. Additional modelling showed that a continuous extraction sequence was a preferred option; subsequently the pre-splitting technique may not be required for the rest of the stopes. However, it would be reasonable to assume that there could be some situations where it might be used as:

- stress-pre-conditioning (destressing) of overstressed pillars

- a means of contour blasting (hangingwall or footwall).

Therefore, some refinement of the drill and blast parameters was required. Spacing of the pre-split holes is calculated as:

$$
S=\frac{d_{b}\left(P_{b}+\sigma_{t}\right)}{\sigma_{t}}
$$

where:

$d_{b}=$ diameter of blasthole $(\mathrm{m})$.

$P_{b} \quad=\quad$ borehole pressure $(\mathrm{Pa})$.

$\sigma_{t} \quad=\quad$ uniaxial tensile strength of rock, which is about $10 \%$ of UCS ( $15 \mathrm{MPa}$ in our case).

The peak borehole pressure is calculated from the following equation:

$$
P_{b}=\frac{\rho_{e} \times V O D^{2}}{8}
$$

where:

$\rho_{e} \quad=\quad$ density of explosive $\left(\mathrm{kg} / \mathrm{m}^{3}\right)$.

VOD $=$ velocity of detonation $(\mathrm{m} / \mathrm{s})$.

Substitution of known values gives:

$$
P_{b}=\frac{800 \times 4200^{2}}{8}=1.8 \mathrm{GPa}
$$

Equation (4) is applicable to fully coupled explosives. For pre-splitting however, de-coupled explosives are generally used. The borehole pressure in this case will be calculated as per Atlas Powder Company (1987): 


$$
P_{b}=\frac{\rho_{e} \times V O D^{2}}{8} \times\left(\frac{d_{e}}{d_{b}}\right)^{2.6}
$$

where:

$d_{e} \quad=\quad$ diameter of explosive $(\mathrm{m})$.

Considering, for example, PN16 polypipe (a stock item at many operations, OD $=75 \mathrm{~mm}, I D=58 \mathrm{~mm}$ ) inserted in a $102 \mathrm{~mm}$ diameter blasthole, peak borehole pressure will be:

$$
P_{b}=1.8 G P a \times\left(\frac{58}{102}\right)^{2.6}=414 M P a
$$

Now spacing between the pre-split holes can be determined:

$$
S=\frac{102 m m \times(414+15)}{15}=2.9 m
$$

To ensure the ground in the pre-splitting plane is sufficiently fractured and the modulus of elasticity of the rock mass is effectively lowered, the spacing between the pre-split holes can be slightly reduced, e.g. to $2.5 \mathrm{~m}$. Recommended pre-splitting blasting parameters are summarised in Table 3.

Table 3 Recommended drill and blast (D\&B) parameters for pre-splitting technique

\begin{tabular}{ccccc}
\hline $\begin{array}{c}\text { Blasthole } \\
\text { Diameter }\end{array}$ & $\begin{array}{c}\text { Explosive } \\
\text { Diameter }\end{array}$ & $\begin{array}{c}\text { Explosive } \\
\text { Density }\end{array}$ & $\begin{array}{c}\text { Blastholes } \\
\text { Spacing }\end{array}$ & $\begin{array}{c}\text { Stand-off From } \\
\text { Hangingwall } \\
\text { Contact }\end{array}$ \\
\hline $102 \mathrm{~mm}$ & $58 \mathrm{~mm}$ & $0.8 \mathrm{~g} / \mathrm{cc}$ & $2.5 \mathrm{~m}$ & $1 \mathrm{~m}$ \\
\hline
\end{tabular}

The stemming depth at the collar should be $2.5 \mathrm{~m}$ (calculated as $12 \times d_{b}$ ). Drilling accuracy of pre-split holes should be as good as possible. Downholes should not break through into the drive below, but stopped at some 2.5-3 m short. All pre-split holes are to be fired on the same delay number, preferably with electronic detonators. The D\&B parameters presented in Table 3 are only recommendations at this stage, as they have not been tested at this mine yet. It should be noted, this technique can be applied to the downhole stoping blocks only, as in the case of the uphole stopes, the charge-up crew cannot work under the blasted rock for safety concerns.

\section{4 Further calibration of extension strain criterion}

Whilst getting 241 stope ready for production, an opportunity was realised to further calibrate the extension strain criterion. Since the ground in the area was notably stressed, cracks in the blastholes were well detectable; the closer to the collar the higher their intensity and greater the aperture. Extension strain was calibrated against the fracture patterns. An example of such calibration is presented in Figure 10. The ground damage classification presented in Table 2 was further reviewed and updated. 

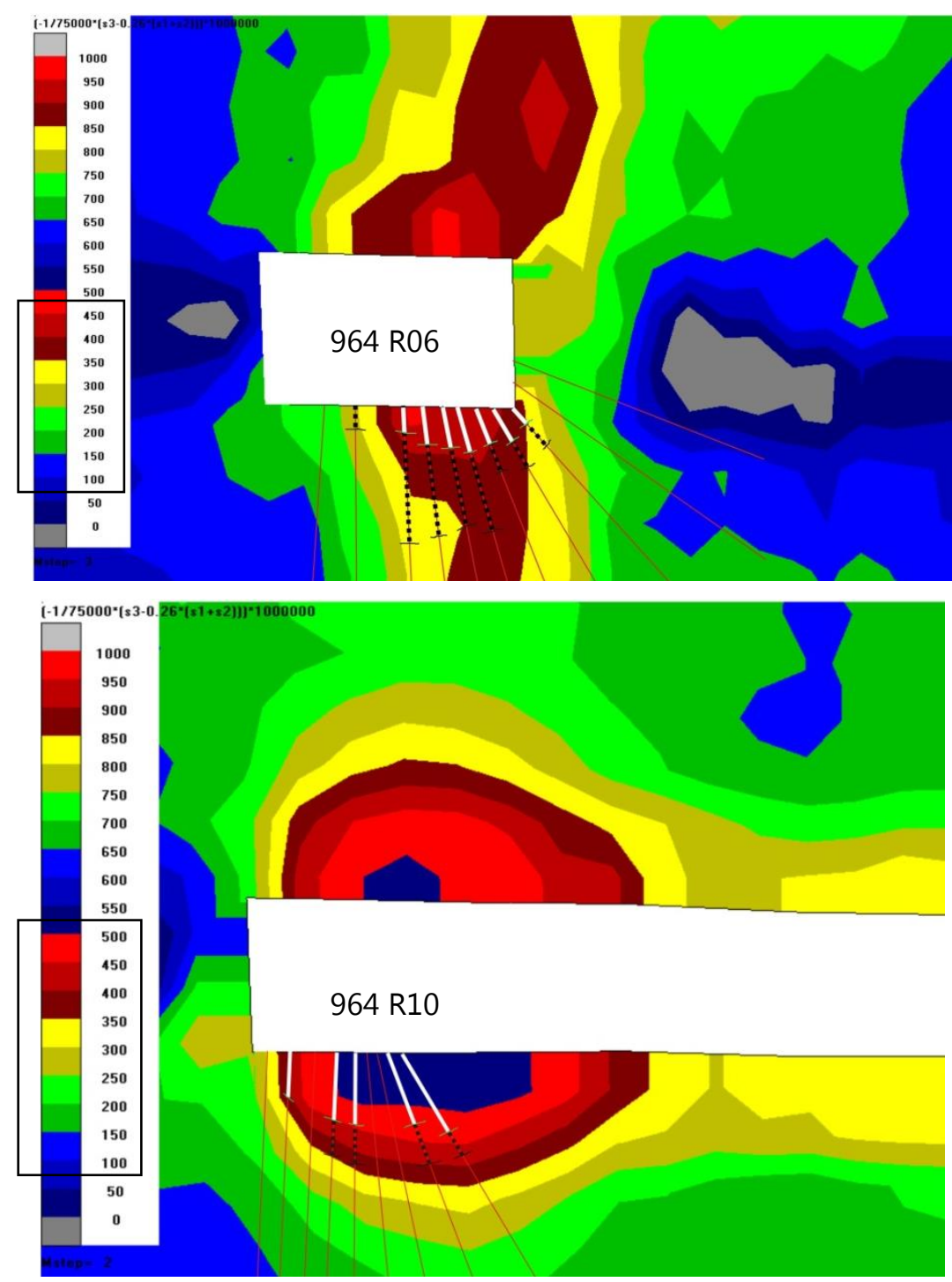

Figure 10 Cracks in production blastholes measured and compared to $\varepsilon_{3}$ contours. White lines - deep distinctive cracks with close spacing, black dashed lines - distance to the first measurable crack

Calibrating numerical models can be as simple as measuring and mapping fractures in the drill holes around underground excavations followed by comparing the fracture intensity with strain contours calculated in a numerical modelling code. As presented in the case study, a well calibrated extension strain criterion can assist in making such a strategic decision as stope extraction sequence.

\section{References}

Atlas Powder Company (1987) Explosives and Rock Blasting, 662 p.

Coulomb, C.A. (1779) Essai sur une application des règles de maximis et minimis à quelques problèmes de statique, relatifs à l'architecture, Mémoires de mathématique et de physique, présentés à l'Académie Royale des Sciences par divers savans, Vol. 7, pp. 343-382.

Dyno Nobel (2010) Blasting and Explosives Quick Reference Guide, viewed 12 April 2011, http://apac.dynonobel.com/files/2010/02/dyno-blasters-handbook-v4.pdf.

Fairhurst, C. (1964) On the validity of the 'Brazilian' test for brittle materials, International Journal of Rock Mechanics and Mining Sciences, Vol. 1, pp. 515-546. 
Fairhurst, C. and Cook, N.G.W. (1966) The phenomenon of rock splitting parallel to the direction of maximum compression in the neighbourhood of a surface, in Proceedings 1st Congress of the International Society for Rock Mechanics, Lisbon, September 25-October 1, Vol. 1, pp. 687-692.

Franklin, J.A. (1971) Triaxial strength of rock material, Rock Mechanics, Vol. 3, pp. 86-98.

Griffith, A.A. (1924) Theory of rupture, in Proceedings 1st International Congress of Applied Mechanics, C.B. Delft Biezeno, J.M. Burges (eds), pp. 55-63.

Hoek, E. and Brown, E.T. (1980) Underground excavations in rock, London: Institute of Mining and Metallurgy.

Holmberg, R. and Persson, P. (1978) The Swedish approach to contour blasting, in Proceedings of Conference on Explosives and Blasting Techniques, Society of Exploration Engineering, February 1-3, New Orleans, USA.

Kuijpers, J. (2000) Fracturing around highly stressed excavations in brittle rock, Journal of the South African Institute of Mining and Metallurgy, Vol. 100, pp. 325-332.

Ndlovu, X. and Stacey, T.R. (2007) Observations and analyses of roof guttering in a coal mine, Journal of the South African Institute of Mining and Metallurgy, Vol. 107, pp. 477-491.

Sheorey, P.R., Biswas, A.K. and Choubey, V.D. (1989) An empirical failure criterion for rocks and jointed rock masses, Engineering Geology, Vol. 26, pp. 141-159.

Stacey, T.R. and De Jongh, C.L. (1977) Stress fracturing around a deep level bored tunnel, Journal of the South African Institute of Mining and Metallurgy, Vol. 78, pp. 124-133.

Stacey, T.R. (1981) A simple extension strain criterion for fracture of brittle rock, International Journal of Rock Mechanics and Mining Sciences, Vol. 18, pp. 469-474.

Wiles, T.D. (2011) Map3D V.57, www.map3d.com. 